\title{
The Development History and Trend of International Agricultural Economics
}

\author{
Cheng Sun ${ }^{1}$ Yunbiao $\mathrm{Li}^{\mathbf{2}^{*}}$
}

1. World Academy of Productivity Science (WAPS), Beijing, 102600, China

2. School of Management, Jilin University, Jilin, Heilongjiang, 130022, China

\begin{tabular}{|c|c|}
\hline ARTICLE INFO & ABSTRACT \\
\hline Article history & Agricultural economics is a science that studies the relations of produc- \\
\hline Received: 19 March 2020 & tion and the laws of productivity in agriculture. International agricultural \\
\hline Revised: 26 March 2020 & economics is to study the agricultural production relations and the laws \\
\hline Accepted: 24 April 2020 & systems, and different historical stages, especially the history and future \\
\hline Published Online: 30 April 2020 & $\begin{array}{l}\text { development trends of agricultural economic development under different } \\
\text { social systems in the East and the West, in order to learn from each other. }\end{array}$ \\
\hline Keywords: & The development of agricultural economic theory and practical experi- \\
\hline Development history & ence, promote the integration of global agricultural economy, improve \\
\hline Trend & logical agriculture, ensure global food and food safety, and improve the \\
\hline International agricultural economics & health of human life. \\
\hline
\end{tabular}

\section{Definition and Connotation of International Agricultural Economics}

$\mathrm{A}$ gricultural economics is a science that studies the relations of production and the laws of productivity in agriculture. International agricultural economics is a science that studies the relationship between agricultural production and the laws of productivity in different regions, countries with different systems, and different historical stages in the world. Agricultural economics is a discipline that studies agricultural production and its related economic activities and economic relations such as exchange, distribution, and consumption. It has rich connotations, including the development and change of production relations in agriculture, the rational organization of various elements of productivity, and the law and application of development and utilization.

The study of the laws of production relations mainly includes the exploration of the ownership of the means of production in agriculture, the position and mutual relationship of people in the production relations, and the circulation and distribution of agricultural products;

The research on the law of productivity operation mainly involves the organization, allocation, communication technology innovation, technological progress, agricultural labor productivity, agricultural machinery productivity, fertilizer utilization rate, organic resource utilization rate, land output rate and other total factor productivity of agricultural productivity. Innovate and upgrade to maximize economic, social and ecological benefits.

In different regions, different countries, and different political systems and systems, the laws and methods of production relations and productivity in agriculture are different, and there are significant differences. The form of ownership of the means of production determines the relations of production, the relations of production de-

*Corresponding Author:

Yunbiao Li,

School of Management, Jilin University, Jilin, Heilongjiang, 130022, China;

E-mail:810427415@qq.com 
termine productivity, and productivity affects total factor productivity.

Through the calculation and international comparison of agricultural total factor productivity in China and other countries in the world, including time and space dimensions, the historical evolution of the international comparison of income and productivity is studied, and the theoretical connotation of agricultural economics and the practical experience of agricultural production are summarized and enriched.

In the research of agricultural economics, the comparative analysis of empirical research on the level of international productivity provides a reference and reference for countries with different regions and different social systems to formulate agricultural economic development plans according to their national conditions, and promotes global agricultural total factor productivity (TFP) improve level.

The international comparative research on agricultural economy provides a basic database and a new scientific perspective, which will contribute to the promotion of global agricultural economic integration, the development of global ecological agriculture, the protection of food security, and the improvement of the quality of life and health of all citizens around the world.

\section{The Development History of International Agricultural Economics}

The research history of international agricultural economics has a long history. The research on economic activities and economic relations in agriculture originated in the period of slave society. The needs of slave owners to manage the manor economy developed in the period of feudal society.

The ancient Chinese agricultural economic thinking mainly emphasized the prosperity of the country and the people at the macro level. It was necessary to "put agriculture first, emphasize agriculture and restrain business" and reduce the tax burden of farmers; at the micro level, it mainly emphasized the development of agricultural production, and made good use of the time and place. , Improve agricultural technology, and carefully manage. Representative works expounding these ideas include Guan Zi and Lu Shi Chun Qiu in the late Warring States period, and Qi Min Yao Shu in the post-Wei Dynasty. In the works of Confucius and Mencius in the Spring and Autumn Period of China, there are many issues concerning agricultural economy, land system, development of agricultural economy, and stability of people's livelihood. At the beginning of the Warring States period, Li Tiao's "method of creating a level of peace", Dong Zhongshu's proposition of "restricting people's name (occupying) the land with insufficient support" in the Han dynasty, and Wang Anshi's policies for young crops, equal transportation, market trade, exemption, farmland water conservancy, etc. It is the representative of agricultural economic thought in the period of Chinese slave society and feudal society.

Modern agricultural economics dates back to China in the 1920s, and many economists and scholars at home and abroad have paid close attention to and studied them, such as Tao Menghe's "Chinese Rural Life", O·E Shell's "Agriculture and China's The Future, FB Taylor's "Research on Rural Economy in China". After the 1930s, the research and teaching of agricultural economics were successively carried out in the Institute of Social Sciences of the Academia Sinica, Nankai University, Jinling University, Zhejiang University, Central University and other institutions. Xu Xuan, Liang Qingchun, Wu Wenhui, Zhang Zhi, etc. successively published many works on the concept of agricultural economics, land issues, and tenant farming issues. The publication of Mao Zedong's "Analysis of Various Classes in Chinese Society" and "An Investigation Report on the Hunan Peasant Movement" opened a new page for China's rural economic problems.

After the founding of the People's Republic of China in 1949 , early research was mainly influenced by the agricultural economics of the former Soviet Union. After 1980, due to more integration of China's rural economic reforms and agricultural development practices, new progress has been made in the research of socialist agricultural economics.

The ancient agricultural economic thoughts of European and Western countries are generally similar to those of ancient China. His representative works include "On Agriculture" by Grand Cato in Roman times and "On Agriculture" by Varro.

However, agricultural economics, as a specialized discipline, gradually formed with the development of capitalism in agriculture. In the middle of the eighteenth century, special works on agricultural economic issues first appeared in the UK, mainly describing the conditions of emerging capitalist agricultural production, and analyzing the advantages of large-scale production in agriculture and the rational allocation of production factors. His representative works include "Agricultural Economy" in the UK.

After the mid-nineteenth century, German agricultural economics works that used abstract methods to study the location allocation of agricultural management and agricultural production appeared, which greatly advanced the research of agricultural economics to the theoretical over- 
view. Its representative work is "Tu Neng" The relationship between isolated countries, agriculture and national economy. After the mid-nineteenth century, agricultural economics in capitalist countries turned to research on the form of agricultural operations, focusing on exploring the rational intensive degree of agricultural production and management and a reasonable departmental structure. Since the 1920s, the United States has become more active in the study of agricultural economics. It mainly studies the principles, principles and methods of how farmers can obtain the greatest profit with the least investment under the conditions of capitalism. It also pays more attention to the transportation and marketing of agricultural products. And research on agricultural finance issues.

After the 1930s, due to the deepening of the economic crisis of capitalism, agriculture was increasingly caught in the threat of violent market fluctuations, and the research of agricultural economics focused on the development of agricultural product market forecasts and the state's intervention and control methods in agricultural production. After the 1950s, capitalist agricultural economics emphasized quantitative analysis. In addition to the more extensive use of statistical methods, mathematical models were also used.

In the course of its development, agricultural economics has a tendency to gradually decompose into many branches. Since the 1950s, agricultural economics has been gradually decomposed into more specialized disciplines such as farm management, agricultural production economics, agricultural transportation and marketing, agricultural finance, land economics, agribusiness management, and agricultural policy.

Under the conditions of the socialist system in China, the research and application of agricultural economics has systematically clarified the laws of the occurrence and development of the socialist agricultural system in order to correctly carry out the socialist transformation and socialist construction of agriculture. It is of great significance for the rational use of agricultural resources and scientific and technological achievements, the improvement of agricultural total factor productivity, and the development from extensive traditional agriculture to high-quality, eco-friendly modern ecological agriculture.

\section{The Development Trend of International Agricultural Economics}

Since the 18th century, human society has experienced three technological revolutions, namely, the first mechanical-led technological revolution that emerged in the 1860s, the second electric-driven technological revolution that emerged in the 1870s, and the 1940s The third technological revolution led by information emerged in the 1940s. While the three scientific and technological revolutions have created a modern industrial system, they have also pushed China to bid farewell to the primitive agriculture era, enter the traditional agriculture era represented by mechanization, fertilizer and pesticide application, and move towards modern agriculture.

Since entering the 21 st century, the world has entered an unprecedented era of intensive innovation and industrial revitalization. Although the regions are different, the political and social systems of the country are different, and the forms of ownership of the means of production are different, there are also significant differences in the laws of movement that constitute the relations of production and the relations of productive forces. However, with the acceleration of global economic integration, global agricultural economic integration has entered a new era of increasing total factor productivity. The concept that science and technology is the primary productivity has become the core of international agricultural economics research. How to improve agricultural labor productivity, Agricultural mechanization productivity, fertilizer utilization rate, organic resource utilization rate, land yield rate, and agricultural economic contribution rate have become the focus of agricultural economic research programs in various countries around the world.

In the 21st century, high and new technology focusing on biotechnology, information technology, new material technology, new energy technology, etc. have developed rapidly, and strategic emerging industries have continued to emerge. They have become the commanding heights of countries occupying technology and competition, and are gaining advantages in international competition. An important support for status. At the same time, the application of high-tech in agriculture has gradually become the cornerstone of supporting the development of world agriculture and the key to enhancing the competitiveness of traditional agriculture, accelerating the transformation of traditional agriculture to modern agriculture, and the subsequent modern ecological agriculture and organic green agriculture, Precision agriculture, digital agriculture, internet agriculture, traditional Chinese medicine agriculture, etc., have all appeared one after another.

At present, with the rapid development of world science and technology, as a leading technology of knowledge enrichment and technology enrichment, agricultural high and new technology has also been endowed with new connotations. It embodies the high-level dynamic relationship of human society to nature and has a powerful the productivity function and social function of the com- 
pany are the leading factors that can bring huge economic, social and ecological benefits to the society and promote the sustainable development of agriculture. In the research of international agricultural economics, the specific future trends are mainly manifested in the following points:

(1) In-depth research on the theoretical direction, development path, and operation methods of total factor productivity science and technology; research and explore new quality management systems and quality statistical evaluation systems that conform to China's new era of innovation, coordination, green, open and shared development concepts; research through technological progress, Scientific and technological innovation to achieve the improvement of production efficiency; research through the innovative combination of agricultural production factors to achieve the improvement of allocation efficiency.

A strategic international scientific and technological innovation cooperation project jointly researched by the famous American scientists Tor Dahl and Asscciates, the Nobel Prize winner in economics and known as the "Father of World Productivity Science", and the international academician consortium and the Beijing Shikemeng Productivity Technology R\&D Center The project "Introduction of the world's advanced total factor productivity science and technology to establish a scientific application system of total factor productivity with Chinese characteristics international cooperation research", for China's proposed "promoting China's economic development quality reform, efficiency change, dynamic change, improve total factor productivity", provide It provides scientific theoretical guidance and practical reference, operating methods and development approaches.

(2) International basic research on agricultural economy represented by agricultural biological genomes, functional genomes and proteomes has become more in-depth, and technological methods continue to innovate and present a trend of rapid development, which has become the most effective way of animal and plant breeding.

Agricultural biotechnology is a series of high and new technologies for targeted and purposeful implementation of agricultural biological genetic improvement and innovation, and biological manufacturing. In this regard, there have been successful cases internationally. The more representative plants include the "Super Hybrid Rice" by Yuan Longping, an academician of the Chinese Academy of Engineering, the Institute of Plant Ecology of China Agricultural University and the International Academician Consortium Elementary Particle Ecology Professional Committee, "Sorrel "Sorrel" Comprehensive Development Industry Research", which has a comprehensive analysis of SOD and Systematic research has been done on the cultivation and processing of the high-protein forage plant "Sorrel", and the sorrel SOD has been in the international leading position. In terms of animal gene and functional gene research, China's representative China Shandong Kelong Animal Husbandry Industry Co., Ltd. "Luxi Yellow Cattle Breeding" and "Black Bone Sheep" distant cross breeding.

In recent years, the United States has successively launched molecular breeding programs for soybeans, wheat, and corn. The International Rice Research Institute (IRRI) and the International Center for Maize and Wheat Improvement (CIMMYT) have organized and implemented molecular breeding programs for rice, corn, and wheat. . In 2006, genetically modified sheep also received European approval, marking that genetically modified animal breeding has begun to enter the application stage. The development of biotechnology and the changes it brings are increasingly being accepted by countries all over the world and gradually moving towards practical applications.

The application of agricultural biotechnology has become a new economic growth point for the development of modern agriculture.

In recent years, the research and development capabilities of microbial fertilizers and microbial pesticides have been continuously improved, and they have been gradually promoted and applied in countries around the world. According to relevant data, there are currently more than 200 active ingredients of biogenic pesticides in the world, more than 11,000 registered products, and product sales reaching nearly US\$3 billion. Microbial fertilizers are constantly innovating, and many varieties are widely used in agriculture. In particular, biotechnology has played a very important role in the improvement of low-yield fields and the remediation of contaminated soil. The representative product is the "Century Tianwang" bio-organic fertilizer which is widely used in Chinese agriculture. It is hailed as the "sacred fertilizer" by Chinese farmers. It is used to increase crop yields, ensure food safety, repair contaminated soil, and control agricultural pollution. Made a huge contribution.

(3) Agricultural informatization, digitalization, and intelligence are changing the mode of agricultural production.

Beginning in the 1990s, developed countries such as Europe and the United States improved the level of agricultural informatization through the adoption of digital agricultural technology, and completely changed the operation mode of traditional agricultural extensive production. In recent years, with the global positioning system (GPS), (Beidou), geographic information system (GIS), continu- 
ous data acquisition sensor (CDS), remote sensing (RS), variable speed self-care equipment (VRT), and decision support system (DSS) The application of technologies such as) in agriculture has made agricultural operations more standardized, refined, efficient, factory-oriented and controllable. A new agricultural model called "Precision Agricuiture" has been used in developed countries in recent years. Gradually emerging, and gradually changing the way of agricultural production and management. The continuous development and application of digital agricultural technology has greatly promoted the development of automation, informatization and intelligent technology of agricultural equipment, and improved the total factor productivity of agriculture.

(4) The deep processing of agricultural products and the integration and breakthrough of marine agricultural high-tech have greatly increased the added value of agricultural products and produced huge economic benefits.

In recent years, China's agricultural product processing technology has developed rapidly, transformation efficiency has been greatly improved, and product quality has improved. The proportion of agricultural product processing industry in the total agricultural output value is increasing year by year. In 2010, it reached 6.31 trillion yuan, surpassing the United States to become the world's largest food manufacturing industry. In 2011, it reached 7.81 trillion yuan, exceeding the national total output value of agriculture, forestry, animal husbandry and sideline fishery. In 2012, the total output value was 8.97 trillion yuan, accounting for about GDP in the same year. 5.8\%. The processing of agricultural products has become an important growth point of the rural economy.

(5) The gradual and widespread application of new material technologies in agriculture is an effective way to improve the utilization of agricultural resources and soil restoration.

In recent years, breakthroughs have been made in new material technology, and the scope of application in agricultural centers has continued to expand, especially in the restoration of obstacles in low-yield fields, the improvement of saline-alkali land, and the restoration of heavy metal contaminated farmland, showing that new materials have very broad application prospects.

Nanomaterials are ultrafine particles, which are called "new materials in the 21 st century, with many special functions." The use of nanomaterials to repair soil and repair polluted water bodies is considered an effective meth- od. For example, the "Century Tianwang" soil-specific nano-remediation material widely used in China is a very representative agricultural material. It can improve soil organic matter, change soil aggregate structure, remove soil harmful heavy metals, degrade chemical pesticide residues, and increase crop yields. There are significant effects in many aspects such as quality. In the improvement of saline-alkali soils, the "Century Tianwang" nano new material project is listed as a key research and development plan (major scientific and technological innovation project) project of Shandong Province, China.

In short, the future research and development trend of international agricultural economics must focus on "ecology, safety, conservation, environmental protection, organic, and pollution-free" for in-depth research and innovation. This is a new major strategic trend for agricultural development.

\section{References}

[1] Zeng Xibai, Li Yongtao, Lin Qi. New Technology for Low-Yield Farm Improvement and Its Development Trend [M]. Beijing: China Science Press, 2017. (in Chinese)

[2] Department of Rural and Social Development, Ministry of Science and Technology of China. New Slow-Release Fertilizer Technology and Application [M]. Taiwan: Taiwan Publishing House, 2006. (in Chinese)

[3] Zhu Daohua. Agricultural Economics [M]. Beijing: China Agriculture Press, 2001. (in Chinese)

\section{About the Author}

Cheng Sun is an academician and researcher of the World Academy of Productivity Science (WAPS). He is currently the Executive Chairman and Secretary-General of the China Branch of the World Productivity Science Alliance, the Chairman of the Executive Committee of the International Federation of Academicians, and the Director of the Academician Studio of the Rural Education Development Center. Published papers and monographs such as "Contemporary Research on the Strategy of Rejuvenating the Country", "New Type of Slow Release Fertilizer Technology and Application", "The Imbalance of Plant Nutritional Growth and Reproductive Growth Balance Is an Important Source of Environmental Pollution Caused by Overuse of Fertilizers". 